\title{
Foramen Magnum Meningioma: a Case Report and Review of Literature
}

\section{Pavao Jurinovic ${ }^{1}$, Ana Repic \\ Bulicic ${ }^{1}$, Marino Marcic ${ }^{1}$, Nikolina Ivica Mise ${ }^{1}$, Marina Titlic ${ }^{1}$, Enra Suljic ${ }^{2}$ \\ ${ }^{1}$ Clinical Department of Neurology, Split University Hospital Center, Split, Croatia \\ 2 Neurological Clinic, Clinical Center of Sarajevo University, Sarajevo, \\ Bosnia and Herzegovina Running header: Foramen magnum meningioma}

Corresponding author: Nikolina Ivica Mise, MD. Clinical Department of Neurology, Split University Hospital Center, Spinciceva 1, HR-21000 Split, Croatia. Phone: +385 91551 8991. E-mail: n_ivica@net.hr

\section{doi: 10.5455/aim.2016.24.74-77}

ACTA INFORM MED. 2016 FEB; 24(1): 74-77 Received: 19 December 2015 • Accepted: 21 January 2016

\begin{abstract}
Introduction: Meningiomas are slow-growing benign tumors that arise at any location where arachnoid cells reside. Although meningiomas account for a sizable proportion of all primary intracranial neoplasms (14.3-19\%), only 1.8 to $3.2 \%$ arise at the foramen magnum. Their indolent development at the craniocervical junction makes clinical diagnosis complex and often leads to a long interval between onset of symptoms and diagnosis. Case report: We report a case of a 79-year-old male patient, presented with ataxia and sense of threatening fainting during verticalization. Magnetic resonance imaging revealed the presence of meningioma in the right side of craniospinal junction.
\end{abstract}

Key words: meningioma, foramen magnum, craniocervical junction, case report

\section{INTRODUCTION}

Meningiomas are extra-axial central nervous system (CNS) tumors that arise from the arachnoid cells of the dura mater. Meningiomas represent 14.3$19 \%$ of all intracranial tumors, the most common non-glial primary intracranial tumor $(1,2)$. They have an annual incidence of six per 100,000 people. An estimated $1-2 \%$ of the population has incidental asymptomatic meningiomas, and in autopsy studies $8 \%$ of these are multiple. The vast majority of meningiomas are benign, slow growing tumors that occur more frequently in women (3-5). The 2:1 female/male ratio observed for intracranial meningiomas is consistent with the increased incidence of meningiomas in post-menopausal women treated with exogenous hormone replacement (6).

Although there are several histological classification systems for meningiomas, the most commonly used is that of the WHO. Benign meningiomas are classified as WHO Grade I, and account for $90 \%$ of cases, whereas atypical (Grade II) and anaplastic (Grade III) meningiomas account for $6 \%$ and $2 \%$ of cases respectively. Only $1.8-3.2 \%$ of all meningiomas are located at foramen magnum (FM). Foramen magnum meningiomas (FMMs) represent a common histological tumor in a rare and elo- quent location. As these tumors are indolent, there occurs a long interval between onset of symptoms and diagnosis (3-5). We report a case of FMM in male patient who presented with ataxia and sense of threatening fainting during verticalization.

\section{CASE REPORT}

A 79-year-old male was admitted to the Department of Neurology from Department of Cardio surgery because of ataxia and sense of threatening fainting during verticalization.

His past medical history was significant. He suffered a stroke 11 years ago with complete recovery. He suffered two myocardial infarctions and after the second infarction there was performed aorto-coronar bypass. Two days after the surgery, that has gone without complication, was noticed that the patient still suffers from inability of verticalization with symptoms of threatening fainting in attempts to sit up. In lying position the patient has no neurologic symptoms.

When he was admitted to Department of Neurology, due to the medical history, magnetic resonance imaging (MRI) was performed. The imaging revealed the presence of intradural meningioma in the right side of FM (Figure 1). The color Doppler flow in- 


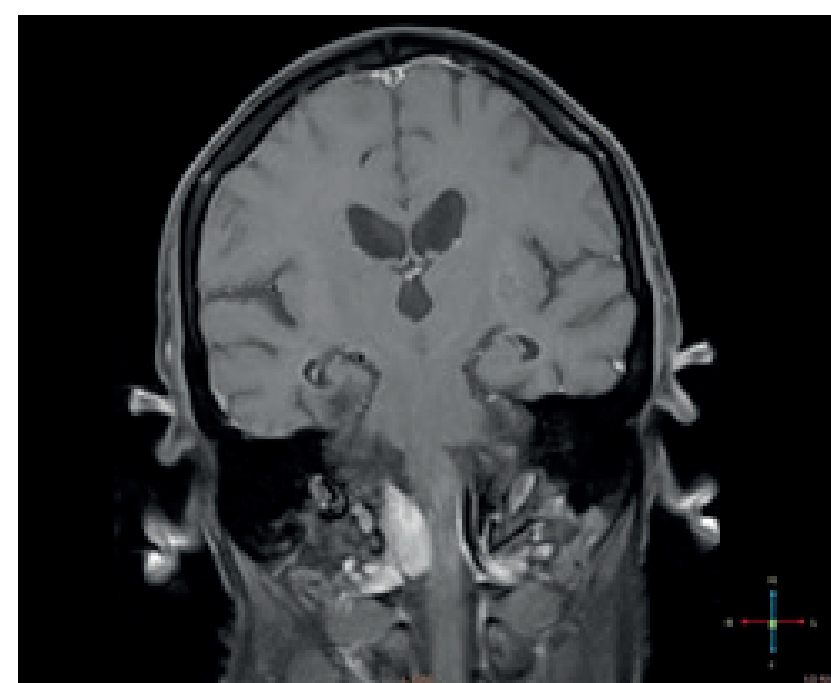

Figure 1. MRI shows intradural meningioma in the right side of foramen magnum, with $2,3 \times 1,3 \mathrm{~cm}$ in size

version revealed very weakened flow in right internal carotid artery, with further significant decline in the flow during the rotation to the left, and a highly significant decrease flow upon rotation to the right and when the patient is sitting.

Neurosurgeon has suggested that the further treatment should be performed with "gamma knife" radiosurgery in University Hospital Center Zagreb.

\section{DISCUSSION}

FMM are those arising anteriorly from the inferior third of the clivus to the superior edge of the $\mathrm{C} 2$ body, laterally from the jugular tubercle to the C2 laminae, and posteriorly from the anterior border of the occipital squama to the spinal process of C2 (7-9). The mean age of the patients with these lesions at the time of diagnosis is approximately 55 years old, but these tumors have been reported in patients of almost every age $(5,6,10-12)$. Although a FMM occurs in children (13). FM contains several critical neuroanatomical and vascular structures. The neural structures include the cerebellar tonsils, inferior vermis, fourth ventricle, caudal aspect of the medulla, lower cranial nerves (CNs) (IX-XII), rostral aspect of the spinal cord, and upper cervical nerves (C-1 and C-2). CN IX through CN XI arise as a series of rootlets along the anterior medulla, with the spinal component of the CN XI arising midway between the anterior and posterior spinal rootlets of the spinal cord. The spinal accessory rootlets coalesce and ascend rostral to join the CN IX, X, and the cranial portion of the CN XI. Together, these nerves exit the skull through the jugular foramen. CN XII exits the medulla more anteriorly than the other lower CNs and passes anterior to the ipsilateral vertebral artery (VA) on its course to the hypoglossal canal, located within the superior and anterior-most portion of the occipital condyle.

Major arterial structures located within the FM include the VAs, posterior inferior cerebellar arteries (PICAs), anterior and posterior spinal arteries, and the meningeal branches of the vertebral, external, and internal carotid arteries. The VA courses through the foramen tranversalis until reaching C-1 where it curves above the lateral aspect of the posterior arch and proceeds rostral to pierce the dura mater just inferior to the lateral edge of the FM adjacent to the occipital con- dyle. Its intradural portion typically gives rise to the posterior spinal artery and PICA, although the origin of the PICA has been reported to vary, arising at, above, or below the FM $(9,14-18)$. Based on the compartment of development FMMs can be classified in intradural, extradural or intra- and extradural. Most of the time, FMMs are strictly intradural. Ten percent have an extradural extension, then they are intra- and extradural, and a few may be entirely extradural $(8,9,19)$. Based on MRI examination, according to the insertion on the dura, FMMs can be classified as anterior if insertion is on both sides of the anterior midline, lateral if insertion is between the midline and the dentate ligament, and posterolateral if insertion is posterior to the dentate ligament. Anterior FMMs displacing the neuroaxis posteriorly, lateral displacing the neuroaxis posterolaterally, and posterolateral displacing the neuroaxis ventrolaterally $(8,9,11)$.

The spinal dentate ligament delineates the anterior and posterior compartments but there is a report of meningioma originating from the dentate ligament (20). Anterior and lateral FMMs are more frequent than posterolateral FMMs (5, 6, $8,19)$. FMMs having the possibility to develop above, below, and on both sides of the VA. Meningiomas are more often located below the VA. In this case, the lower CNs are always pushed cranially and posteriorly. On the other hand, if the lesion grows above the VA, the position of the lower CNs cannot be anticipated; the nerves may be displaced separately in any direction. In case of tumoral development on both sides of the VA, a similar problem may exist with the position of the lower CNs. Moreover, the dura around the VA penetration may be infiltrated by the tumor $(8,9,19)$.

The lesion is often large when discovered because of their slow-growing rate, their indolent development, the difficulty of the diagnosis leading to a long interval since the first symptom, and the wide subarachnoid space at this level (14). The clinical presentation of FMM is protean, and the mean length of symptoms prior to diagnosis is 30.8 months, even in the era of MRI $(8,14)$. Trauma to the head or neck occasionally caused these tumors to manifest themselves before they otherwise would have been detected (21). Indeed, prior to the advent of advanced imaging technologies, patients with FM tumors were frequently misdiagnosed with a variety of disorders including multiple sclerosis, cervical spondylosis, a herniated cervical disk and amyotrophic lateral sclerosis because of the uncommon symptoms caused by the anterior location of the lesion $(22,23)$. Signs and symptoms presented at admission are unusual, atypical, slowly progressing, and, often, remitting.

The first category of the symptoms includes occipital and posterior cervical pain and hyperesthesia in the C2 dermatome $(5,10,24-28)$. This pain is the most salient initial manifestation of the tumor, usually exacerbated by neck manipulation or by maneuvers that raise the intracranial pressure, such as coughing, straining, or sneezing $(21,29)$. The second category of the symptoms includes limb weakness and sensory deficits $(5,10,24-28)$. Classic FM syndrome is defined by development of unilateral arm sensory and motor deficits, which progress to the ipsilateral leg, then the contralateral leg, and finally contralateral upper extremity (14, 30). Gait disturbances, diplopia, dysphagia, dysarthria, dyspnea, sphincter disturbances, vomiting, nausea are some of 
the common symptoms $(5,10,24-28)$. The most common neurological sign is hyperreflexia, followed by weakness of the extremities in all combinations (hemiparesis/plegia, quadriparesis/plegia) and sensory loss. The Babinski sign, a gait disturbances, or lower CN (IX-XI) palsies are present in approximately half of patients with this tumor. CN XI is most commonly affected, presented by the shoulder weakness because of atrophy of sternocleidomastoids and trapezius muscles. Dissociated sensory loss, loss of coordination in the hands, Brown-Sequard syndrome, down-beating nystagmus, and nuchal rigidity and tenderness occur in one quarter to one third of patients. Papilledema, Horner's syndrome, and dysarthria are less common neurological findings (25). MRI is the most useful method in preoperative diagnosis, and it is helpful to precisely delimit the dural attachment zone and tumor relation to neural and vascular structures. Cerebral angiography should also be performed to confirm the feeding vessels and if highly vascularized tumor is suspected $(9,25$, 31).

FMM affect the cerebrovascular system, but there is no case reports of FMM presented as threatening fainting during verticalization. We present a unique symptomatology of the FMM. The relationship of the tumor to neighboring structures, i.e., the VA in particular, determines its resectability but also influence the clinical presentation (24). The rate of VA encasement can be 33-61\% (4, 5, 32-34). FMM can appears in the form of the initial symptoms of a pontine stroke due to a vascular disorder but also tumors in close proximity to the ventrolateral medulla oblongata may induce neurogenic hypertension, similar to neurovascular compression (35-37).

\section{CONCLUSION}

In this case, thorough history and physical examination with subsequent imaging allowed for definitive therapy with full resumption of the patient's normal daily activities. Because of its rarity prompt diagnosis of the compressive lesion is difficult and hence may be delayed. The early diagnosis of compressive lesions is important not only because this offers the possibility of curing the condition, but also because an unrecognized FM mass is a potentially lethal condition. Careful evaluation of the upper cervical spine and posterior fossa is therefore mandatory.

Author's contribution: author and all co-authors of this paper have contributed in all phases if it's preparing. Final proof reading was made by first author.

Conflict of Interest: No conflict of interest was declared by the authors.

\section{REFERENCES}

1. Akalan N, Seçkin H, Kiliç C, Ozgen T. Benign extramedullary tumors in the foramen magnum region. Clin Neurol Neurosurg. 1994; 96(4): 284-9.

2. Wara WM, Sheline GE, Newman H, Townsend JJ, Boldrey EB. Radiation therapy of meningiomas. Am J Roentgenol Radium Ther Nucl Med. 1975; 123: 453-8.

3. Meyer FB, Ebersold MJ, Reese DF. Benign tumors of the foramen magnum. J Neurosurg. 1984; 61(1): 136-42.

4. Arnautovic KI, Al-Mefty O, Husain M. Ventral foramen mag- num meninigiomas. J Neurosurg. 2000; 92: 71-80.

5. Colli BO, Carlotti-Junior CG, Assirati-Junior JA, Borba LA, Coelho-Junior Vde P, Neder L. Foramen magnum meningiomas: surgical treatment in a single public institution in a developing country. Arq Neuropsiquiatr. 2014; 72(7): 528-37.

6. Pirotte BJ, Brotchi J, DeWitte O. Management of anterolateral foramen magnum meningiomas: surgical vs conservative decision making. Neurosurgery. 2010; 67(3): 58-70.

7. Göçmez C, Göya C, Hamidi C, Kamaşak K, Yilmaz T, Turan $\mathrm{Y}$, et al. Three-dimensional analysis of foramen magnum and its adjacent structures. J Craniofac Surg. 2014; 25(1): 93-97.

8. George B, Lot G, Boissonnet H. Meningioma of the foramen magnum: a series of 40 cases. Surg Neurol. 1997; 47(4): 371-9.

9. Bruneau M, George B. Foramen magnum meningiomas: detailed surgical approaches and technical aspects at Lariboisière Hospital and review of the literature. Neurosurg Rev. 2008; 31(1): 19-33.

10. Flores BC, Boudreaux BP, Klinger DR, Mickey BE, Barnett SL. The far-lateral approach for foramen magnum meningiomas. Neurosurg Focus. 2013; 35(6): E12. doi:10.3171/2013.10.FOCUS13332.

11. Borba LA, de Oliveira JG, Giudicissi-Filho M, Colli BO. Surgical management of foramen magnum meningiomas. Neurosurg Rev. 2009; 32(1): 49-60.

12. Goel A, Desai K, Muzumdar D. Surgery on anterior foramen magnum meningiomas using a conventional posterior suboccipital approach: a report on an experience with 17 cases. Neurosurgery. $2001 ;$ 49(1): 102-7.

13. Menezes AH. Surgical approaches: postoperative care and complications "posterolateral-far lateral transcondylar approach to the ventral foramen magnum and upper cervical spinal canal". Childs Nerv Syst. 2008; 24(10): 1203-7.

14. Boulton MR, Cusimano MD. Foramen magnum meningiomas: concepts, classifications, and nuances. Neurosurg Focus. 2003; 14(6): e10.

15. Rhoton AL. Jr. The foramen magnum. Neurosurgery. 2000; 47(3Suppl): S155-93.

16. Vallée B, Besson G, Houidi K, Person H, Dam Hieu P, Rodriguez $\mathrm{V}$, et al. Juxta-or trans-condylar lateral extension of the posterior suboccipital approach. Anatomical study, surgical aspects. Neurochirurgie. 1993; 39(6): 348-59.

17. George B. Value and control possibilities of the vertebral artery in tumor surgery at the base of the skull. Ann Otolaryngol Chir Cervicofac. 1992; 109(3): 156-61.

18. George B, Dematons C, Cophignon J. Lateral approach to the anterior portion of the foramen magnum. Application to surgical removal of 14 benign tumors: technical note. Surg Neurol. 1988; 29(6): 484-90.

19. Bruneau M, George B. Classification system of foramen magnum meningiomas. J Craniovertebr Junction Spine. 2010; 1(1): 10-17.

20. Jung TY, Jung S, Kim IY, Kang SS. Foramen magnum meningioma originating from the dentate ligament. Acta Neurochir (Wien). 2009; 151(4): 385-88.

21. Weintraub MI. Dormant foramen magnum meningioma 'activated' by chiropractic manipulation. N Y State J Med. 1983; 83(8-10): 1039-40.

22. Howe JR, Taren JA. Foramen magnum tumors. Pitfalls in diagnosis. JAMA. 1973;225:1061-6.

23. Sawaya RA. Foramen magnum meningioma presenting as amy- 
otrophic lateral sclerosis. Neurosurg Rev. 1998; 21: 277-80.

24. Mei-Hua L, Geng-Sheng X, Zhi-Qun J, Yi-Yun L, Tao H. Supracondylar transjugular tubercle approach to intradural lesions anterior or anterolateral to the craniocervical junction without resection of the occipital condyle. Turk Neurosurg. 2013; 23(2): 202-7.

25. Komotar RJ, Zacharia BE, McGovern RA, Sisti MB, Bruce JN, D'Ambrosio AL. Approaches to anterior and anterolateral foramen magnum lesions: A critical review. J Craniovertebr Juncion Spine. 2010; 1(2): 86-99.

26. Imamura J, Ikeyama Y, Tsutida E, Moroi J. Transoral transclival approach for intradural lesions using a protective bone baffle to block cerebrospinal fluid pulse energy-two case reports. Neurol Med Chir. (Tokyo) 2001; 41(4): 222-6.

27. Banerji D, Behari S, Jain VK, Pandey T, Chhabra DK. Extreme lateral transcondylar approach to the skull base. Neurol India. 1999; 47(1): 22-30.

28. Kanai M, Kawano K, Uehara S. A case of foramen magnum meningioma in which case enhanced three-dimensional CT scan was valuable for preoperative evaluation of the surgical approach. No Shinkei Geka. 1997; 25(7): 641-5.

29. Rhoton AL Jr. Meningiomas of the cerebellopontine angle and foramen magnum. Neurosurg Clin N Am. 1994; 5(2): 349-77.

30. Fujita K, Matsumoto S. Meningioma of foramen magnum-report of two dases and review of reference: its clinical manifes- tations (author's transl). No Shinkei Geka. 1975; 3(9): 763-8.

31. Iseda T, Goya T, Nakano S, Wakisaka S. Magnetic resonance imaging and angiographic appearance of meningioma of the fourth ventricle-two case reports. Neurol Med Chir. (Tokyo) 1997; 37(1): 36-40.

32. Bassiouni H, Ntoukas V, Asgari S, Sandalcioglu EI, Stolke D, Seifert V. Foramen magnum meningiomas: clinical outcome after microsurgical resection via a posterolateral suboccipital retrocondylar approach. Neurosurgery. 2006; 59: 1177-87.

33. Crockard HA, Sen CN. The transoral approach for the management of intradural lesions at the craniocervical junction: review of 7 cases. Neurosurgery. 1991; 28: 88-98.

34. Pamir MN, Kilic T, Ozduman K, Ture U. Experience of a single institution treating foramen magnum meningiomas. J Clin Neuroscience. 2004; 11(8): 863-7.

35. Samii M, Klekamp J, Carwalho G. Surgical results for meningioma of the craniocervical junction. Neurosurgery. 1996; 39 : 1086-94.

36. Manzano-Palomo MS, Egido JA. Pontine stroke secondary to a foramen magnum meningioma. Rev Neurol. 2005; 40(11): 668-70.

37. Wörner BA, Rahim T, Lange M, Fink U, Oeckler R. Long-lasting improvement of arterial hypertension after surgical treatment of a foramen magnum meningioma: case report. Surg Neurol. 2002; 58(3-4): 189-93.

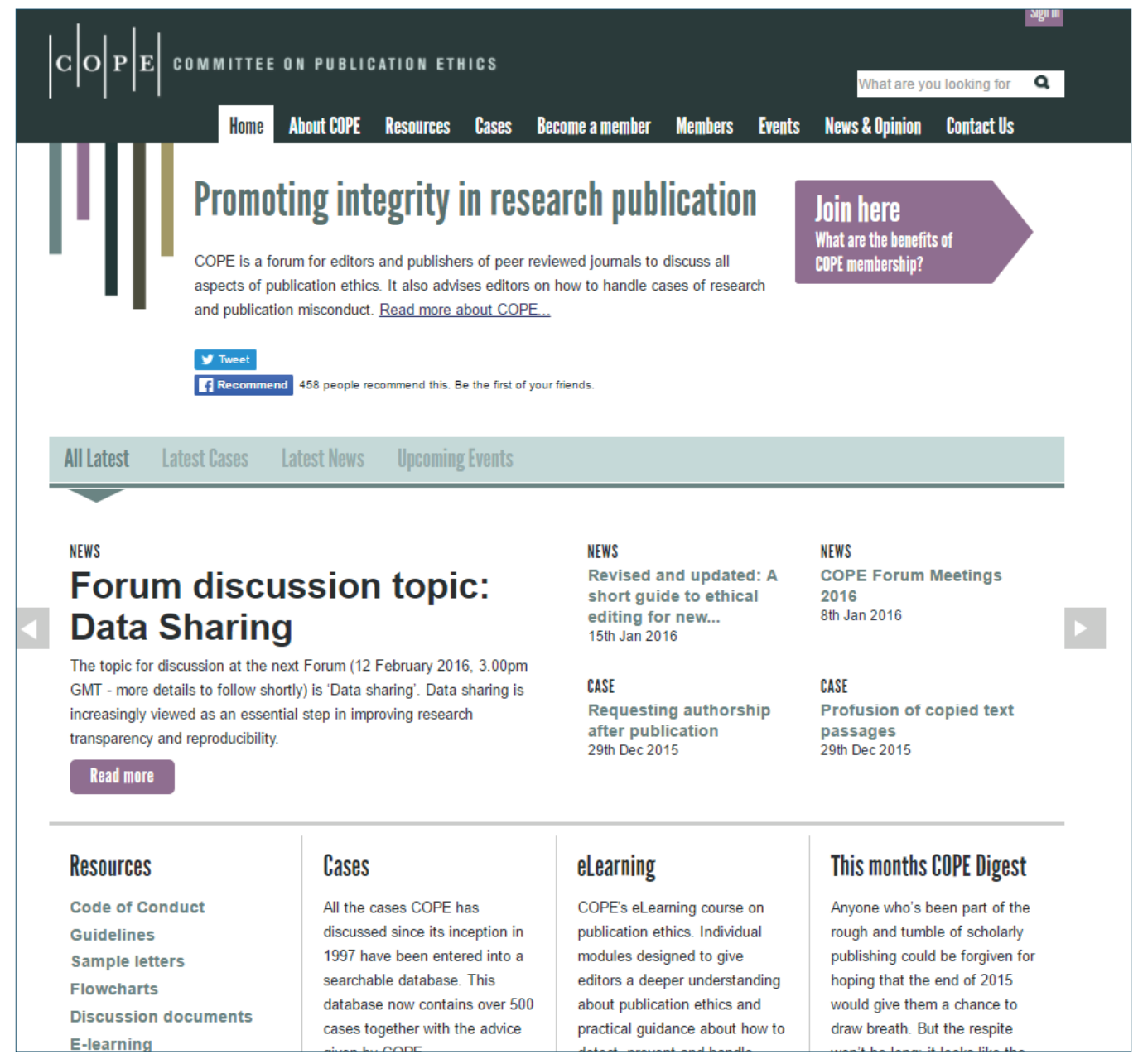

